\title{
FORAGING AND NESTING ECOLOGY OF A COSTA RICAN LEAF-CUTTING ANT, ACROMYRMEX VOLCANUS
}

\author{
BY JAMES K. WeTteRER \\ Museum of Comparative Zoology, \\ Harvard University, \\ Cambridge MA 02138
}

\begin{abstract}
INTRODUCTION
Leaf-cutting ants (Tribe Attini: Atta spp. and Acromyrmex spp.) have extremely polymorphic workers and a complex division of labor among size-castes (Wilson, 1980a, b). Foraging is generally performed by medium to large-size workers. At the nest, smaller workers prepare the retrieved material as a substrate for growing a fungus that the ants use for food. One characteristic generally considered to distinguish the two genera of leaf-cutters is that only Atta species produce a soldier caste of large workers whose primary function is nest defense (Weber, 1972).

In earlier studies, I examined the foraging ecology of Atta cephalotes (L.) and Acromyrmex octospinosus echinatior Forel at La Selva Biological Station in Costa Rica (Wetterer, 1990a, b, 1991a, b, ms). In the present study, I examined a third species of leaf-cutting ant common in this area, Acromyrmex volcanus Wheeler (Wheeler, 1937).

A. cephalotes and Ac. octospinosus at La Selva show distinct ecological differences. A. cephalotes foragers usually carry fresh leaf fragments cut from large trees (also see Rockwood and Hubbell, 1987; Vasconcelos, 1990). In contrast, Ac. octospinosus foragers primarily cut herbs and scavenged on fallen leaves, fruits, flowers, and other plant material (Wetterer, 1991b). Compared with A. cephalotes, Ac. octospinosus foragers are on average larger and have a narrower range of body mass (Wetterer, 1991b).

No previous study has examined the ecology of Ac. volcanus. My preliminary work indicated that Ac. volcanus is much like its close relative Ac. octospinosus. Ac. volcanus foragers, however,
\end{abstract}

Manuscript received 27 March 1993. 
are much larger in size and much darker in color than Ac. octospinosus foragers.

In the present study, I measured forager mass, substrate selectivity, and load size for Ac. volcanus foragers in the field. I compared these data with the findings from my earlier work with $A c$. octospinosus. In addition, I located the nests of Ac. volcanus to describe and evaluate their nesting habits.

\section{MeTHODS}

The only previous published work on Ac. volcanus was its description based on seven foragers collected on "Volcán de Barba" (Volcán Barva) in Costa Rica (Wheeler, 1937). Wheeler (1937) originally gave this ant the name Ac. octospinosus volcanus. However, because Ac. volcanus lives sympatrically with Ac. octospinosus echinatior yet remains completely distinct, it must be considered a separate species. A revision of the attine ants of Central America is currently in preparation (J. Longino, unpublished).

My three study sites were all located on Volcán Barva, in Northcentral Costa Rica: La Selva Biological Station situated at the base of the volcano (altitude: $40 \mathrm{~m}$ ), Plastico Biological Station (altitude: $560 \mathrm{~m}$ ) and Rara Avis Reserve (altitude: $700 \mathrm{~m}$ ). In addition to Ac. volcanus, I have found three other leaf-cutter species at these sites: Ac. octospinosus and A. cephalotes at La Selva and Plastico, and Ac. coronatus at Plastico and Rara Avis (Wetterer unpublished). Ac. volcanus is currently known from only one other site, Tortuguero National Park in Northeastern Costa Rica (J. Longino, personal communication).

I collected foragers at six colonies of Ac. volcanus: three at $\mathrm{La}$ Selva (colonies L1, L2, and L3), one at Plastico (colony P), and two at Rara Avis (colonies R1 and R2). In July 1989 (wet season) and January 1991 (dry season) I collected foragers from colony L1. In June and July 1992 (wet season) I collected from colonies P and R1. In February 1993 (dry season) I collected from colonies P, R1, $\mathrm{R} 2$, L2, and L3.

At each colony I collected consecutive ants on the main foraging trail. I placed each ant with her load in a separate vial. I weighed each ant and load to the nearest $0.1 \mathrm{mg}$ on a Mettler Balance, and scored each load as fresh (soft, pliant, and green) or fallen (dry or yellowed) leaf material (fragment or whole leaf), 
herb section (stem or stem with leaves, leaf buds, or flowers), flower (part or whole), fruit (part or whole berry) or "other."

At each colony I followed laden foragers in order to locate their nests. In addition, I partially excavated several nests.

\section{RESULTS}

\section{Foraging selectivity}

Ac. volcanus foragers carried a wide variety of vegetable matter (Table 1). I never found Ac. volcanus foragers cutting the leaves of large trees. The fresh leaf material that the ants cut came primarily from leaves of herbs. (The fresh leaf fragments of colony L3, however, were cut from the thick succulent leaves of an epiphyte.) Foragers also commonly cut whole sections of herbs (herb stems and stems with leaves, leaf buds, or flowers). In addition, the foragers cut pieces of fallen leaves, fruits, and petals, and gathered fallen berries and flower buds, plus variable amounts of other types of plant material (petioles, seeds, bark, and wood slivers). Also, at colony L1, I collected two Ac. volcanus foragers carrying small whole mushrooms. The ants at colony $\mathrm{P}$ in the wet season carried the highest proportion of dry leaf material. These consisted of fragments of grass blades dropped by $A$. cephalotes foragers near the entrance of a neighboring colony.

Table 1. Foraging selectivity by six different colonies of Acromyrmex volcanus compared with Acromyrmex octospinosus (from Wetterer 1991b). Season: $\mathrm{W}=$ wet, $\mathrm{D}=$ dry.

\begin{tabular}{|c|c|c|c|c|c|c|c|c|}
\hline colony & season & (n) & $\begin{array}{c}\% \text { fresh } \\
\text { leaf }\end{array}$ & $\begin{array}{c}\% \text { fallen } \\
\text { leaf }\end{array}$ & $\begin{array}{l}\% \text { herb } \\
\text { section }\end{array}$ & $\%$ flower & $\%$ fruit & $\%$ other \\
\hline L1 & W & (29) & 28 & 10 & 10 & 14 & 28 & 10 \\
\hline L1 & $\mathrm{D}$ & (25) & 28 & 0 & 36 & 24 & 0 & 12 \\
\hline L2 & D & (25) & 68 & 4 & 4 & 24 & 0 & 0 \\
\hline L3 & D & (25) & 52 & 4 & 8 & 36 & 0 & 0 \\
\hline $\mathbf{P}$ & W & (25) & 32 & 24 & 4 & 28 & 0 & 12 \\
\hline $\mathbf{P}$ & D & (25) & 28 & 8 & 56 & 0 & 8 & 0 \\
\hline R1 & W & (35) & 14 & 3 & 6 & 60 & 6 & 11 \\
\hline R1 & D & (25) & 52 & 4 & 0 & 40 & 4 & 0 \\
\hline R2 & D & (35) & 0 & 12 & 16 & 60 & 4 & 12 \\
\hline \multicolumn{9}{|l|}{ Total } \\
\hline \multirow{2}{*}{\multicolumn{2}{|c|}{$\begin{array}{l}\text { Ac. volcanus } \\
\text { Ac. octospinosus }\end{array}$}} & (239) & 33 & 8 & 15 & 33 & 6 & 7 \\
\hline & & (275) & 23 & 17 & 9 & 19 & 27 & 5 \\
\hline
\end{tabular}


The general character of the vegetable material gathered by $A c$. volcanus foragers was similar to that gathered by the $A c$. octospinosus foragers (Table 1). However, the nature of fruit and flowers carried by the two species of Acromyrmex differed. Ac. volcanus foragers often took whole berries and whole flowers, whereas Ac. octospinosus foragers carried small pieces cut from larger fruits and flower petals (Wetterer, 1991b).

\section{Forager mass}

For all Ac. volcanus colonies combined, forager mass ranged from 19.1 to $41.5 \mathrm{mg}$, a 2.2-fold range. Mean forager mass varied somewhat among Ac. volcanus colonies (Table 2). This variation was consistent between wet and dry seasons. Each Ac. volcanus colony had a very narrow size-range of workers out foraging, from a $26 \%$ difference in mass between the smallest and largest forager to a $213 \%$ difference.

The Ac. volcanus foragers were considerably larger than Ac. octospinosus foragers (Figure 1; Table 2). Weber (1972) reported that Ac. octospinosus was the largest of all Acromyrmex species with maxima workers weighing up to $15.6 \mathrm{mg}$. Wetterer (1991b) reported Ac. octospinosus foragers with masses of up to $21.2 \mathrm{mg}$

Table 2. Forager polymorphism and load size in Acromyrmex volcanus compared with Acromyrmex octospinosus (from Wetterer 1991b). Mean and range of forager mass $\left(m_{\mathrm{A}}\right.$ in mg), coefficient of variation $(\mathrm{CV})$, mean relative burden $\left(B=m_{\mathrm{L}} / m_{\mathrm{A}}\right)$, and the logarithmic relation between ant mass and load mass $\left(m_{\mathrm{L}}\right.$ in $\left.\mathrm{mg}\right)$. For colony $\mathrm{L}, \mathrm{W}=$ wet season, $\mathrm{D}=$ dry season. ${ }^{*}=\mathrm{P}<0.05, * *=\mathrm{P}<0.001$ (Sample sizes as in Table 1).

\begin{tabular}{lcccccc}
\hline colony & $m_{\mathrm{A}} \pm \mathrm{SD}$ & range & $\mathrm{CV}$ & $B \pm 1 \mathrm{SD}$ & $\log m_{\mathrm{L}}$ regression & $\mathrm{R}^{2}$ \\
\hline $\mathrm{L} 1(\mathrm{~W})$ & $30.2 \pm 1.9$ & $27.0-34.0$ & 0.06 & $1.9 \pm 1.2$ & $0.9+0.5 \log m_{\mathrm{A}}$ & 0.00 \\
$\mathrm{~L} 1(\mathrm{D})$ & $31.4 \pm 1.9$ & $27.4-35.4$ & 0.06 & $1.2 \pm 0.9$ & $0.2+0.8 \log m_{\mathrm{A}}$ & 0.00 \\
$\mathrm{~L} 2$ & $25.8 \pm 2.6$ & $21.9-30.4$ & 0.10 & $1.3 \pm 1.2$ & $1.5-0.2 \log m_{\mathrm{A}}$ & 0.00 \\
$\mathrm{~L} 3$ & $34.6 \pm 2.4$ & $30.4-37.8$ & 0.07 & $2.0 \pm 1.1$ & $6.4-3.0 \log m_{\mathrm{A}}$ & 0.09 \\
$\mathrm{P}(\mathrm{W})$ & $27.1 \pm 1.8$ & $23.9-30.2$ & 0.07 & $0.6 \pm 0.3$ & $1.5-0.3 \log m_{\mathrm{A}}$ & 0.00 \\
$\mathrm{P}(\mathrm{D})$ & $26.2 \pm 2.3$ & $20.5-30.5$ & 0.09 & $0.9 \pm 0.6$ & $-0.8+1.4 \log m_{\mathrm{A}}$ & 0.04 \\
$\mathrm{R} 1(\mathrm{~W})$ & $33.4 \pm 4.9$ & $19.1-40.7$ & 0.14 & $1.0 \pm 0.7$ & $-1.4+1.8 \log m_{\mathrm{A}}$ & $0.14^{*}$ \\
$\mathrm{R} 1(\mathrm{D})$ & $34.4 \pm 4.2$ & $22.6-41.5$ & 0.12 & $1.2 \pm 0.6$ & $-0.4+1.3 \log m_{\mathrm{A}}$ & 0.06 \\
$\mathrm{R} 2$ & $31.3 \pm 2.7$ & $24.8-36.5$ & 0.09 & $1.1 \pm 1.1$ & $2.8-1.0 \log m_{\mathrm{A}}$ & 0.01 \\
Total & & & & & & \\
Ac. volcanus & $30.6 \pm 4.3$ & $19.1-41.5$ & 0.14 & $1.2 \pm 1.0$ & $-1.3+1.9 \log m_{\mathrm{A}}$ & $0.08^{* *}$ \\
Ac. octospinosus & $13.3 \pm 4.2$ & $4.0-21.2$ & 0.31 & $1.4 \pm 1.2$ & $-0.5+1.4 \log m_{\mathrm{A}}$ & $0.16^{* *}$ \\
\hline
\end{tabular}




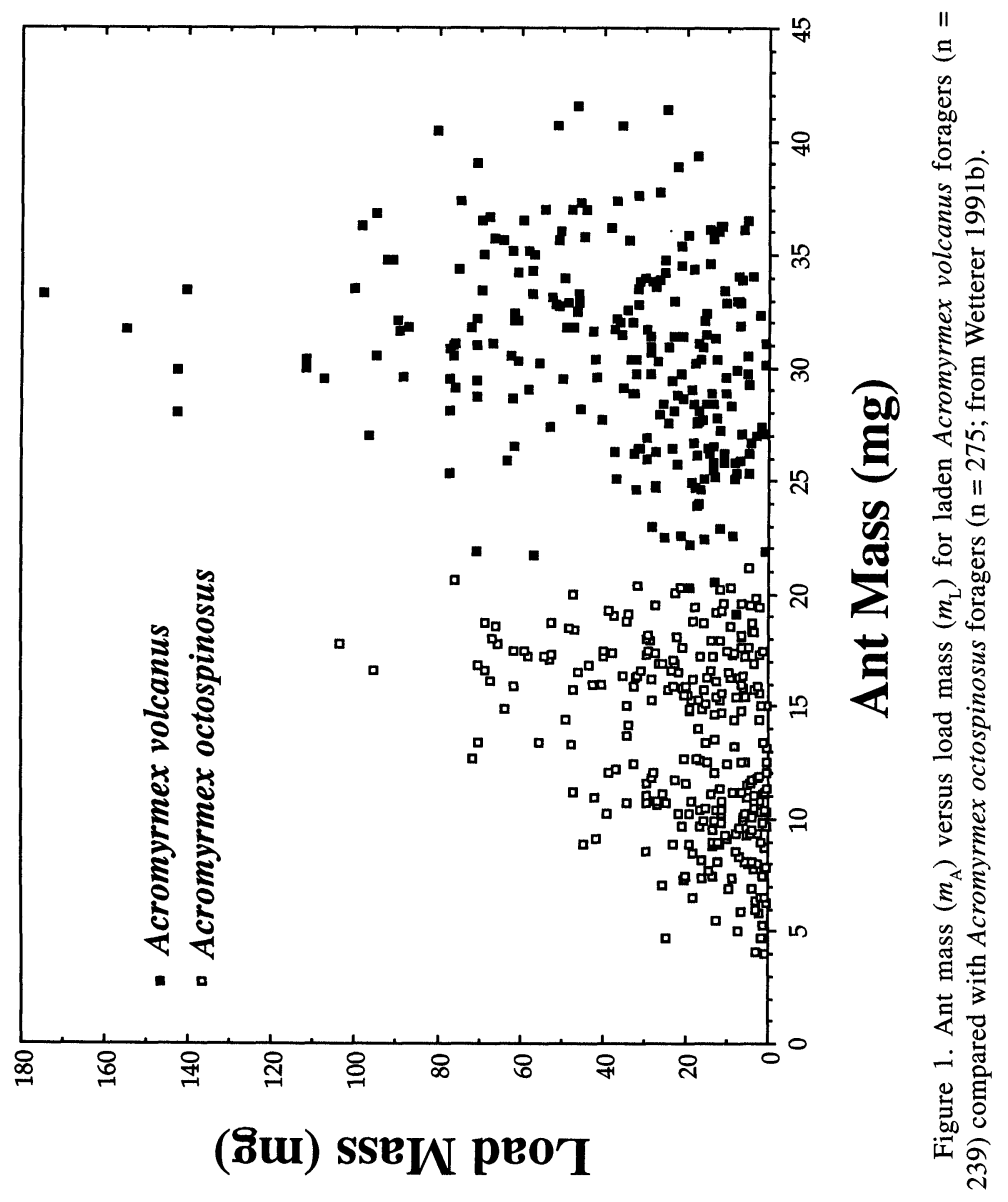


(Table 2). In the present study, I found that all colonies of Ac. volcanus had foragers of even greater mass than the largest Ac. octospinosus observed by Weber (1972) and Wetterer (1991b). In fact, one colony of Ac. volcanus had foragers up to $41.5 \mathrm{mg}$ in mass, more than twice the maximum reported by Weber (1972) for Ac. octospinosus.

\section{Load-mass selectivity}

Foragers from individual colonies of Ac. volcanus showed very little correlation between ant mass $\left(m_{\mathrm{A}}\right)$ and load mass $\left(m_{\mathrm{L}}\right)$ (Table 2). In part, this is a result of the narrow size-range of foragers within a colony. Combining across colonies, however, there was a significant positive correlation between ant mass and load mass (Table 2, Figure 1).

Burden (load mass/ant mass) ranged from 0.03 to 5.2. Only $2 \%$ of the ants carried loads greater than four times their own mass (Figure 1). Overall, Ac. volcanus foragers carried loads that averaged 1.2 times their own mass (Table 2). Mean burden varied among colonies, largely due to differences in load type. For example, the lowest mean burden was for colony P (wet season) where a large portion of the ants carried very light pieces of dried grass and fragments from thin fern leaves. The greatest mean burdens were at colony L1 (wet season) where many ants carried whole berries and at colony L3 where many ants carried whole flower buds and fresh fragments cut from the thick leaves of an epiphyte.

The overall pattern of load mass selection by Ac. volcanus foragers was similar to that of Ac. octospinosus foragers (Table 2; for Ac. octospinosus, mean burden $=1.4$, range $=0.02-5.8,5 \%$ with burdens greater than 4; Wetterer 1991b). However, because Ac. volcanus foragers were on average more than twice the mass of $A c$. octospinosus foragers (Table 2), their average load mass was about twice as large (mean load mass was $36.5 \pm 29.8 \mathrm{mg}$ for Ac. volcanus versus $19.5 \pm 18.8 \mathrm{mg}$ for Ac. octospinosus).

\section{Nesting habits}

In addition to the six colonies examined above, I located seven additional Ac. volcanus colonies: two at La Selva, two at Plastico, and three at Rara Avis. The La Selva and Rara Avis colonies were all located in primary forest. The Plastico colonies were all located in open pasture. 
At La Selva, all Ac. volcanus nests appeared to be situated up in trees. All laden foragers disappeared into the canopy, usually via several vines hanging from a large tree. Only once did I actually find an Ac. volcanus nest at La Selva. It was set under a pile of organic debris in the crotch between tree limbs. At the other Ac. volcanus colonies, I was unable to find laden foragers descending any nearby trees, so I presumed the nests were in the trees that the ants were ascending. J. Longino (personal communication) found one nest of Ac. volcanus at La Selva, and it was under organic debris in the crotch of a tree.

There were no large trees at Plastico. Instead, all three nests of Ac. volcanus that I located there were at the top edge of road banks directly under the root mats of the grass, ferns, and herbs. Colony $\mathrm{P}$ was bordered on two sides by $A$. cephalotes nests (both with entrances lower in the road bank). The foraging trails of colony $\mathbf{P}$ appeared to end at the nest entrances of these two other colonies suggesting possible interspecific territoriality.

At Rara Avis, two of the five Ac. volcanus colonies (colony R2 and one other) were apparently in trees. The other three colonies were on the ground under organic debris: colony R1 was at the base of a rotted tree trunk under about $15 \mathrm{~cm}$ of organic debris, a second colony was in the roots of a stilted palm, and a third was under a pile of debris from a rotted log. Curiously, the first two of these colonies on the ground were located within $40 \mathrm{~cm}$ of a nest of Paraponera clavata, the highly aggressive "bala" ant. At La Selva I have often seen $P$. clavata foragers on trails of both $A c$. volcanus and Ac. octospinosus, suggesting a possible association.

Thus, at each of the three sites, Ac. volcanus showed different nesting habits. In all cases, however, the nests were built not under soil, but under loose organic debris.

When I excavated a nest, large workers that function as foragers streamed out and attacked my hands. Although these workers were the size of small $A$. cephalotes soldiers, their bites were relatively feeble in comparison to equivalent-sized A. cephalotes soldiers, which easily draw blood.

Whereas I found only very large Ac. volcanus workers foraging, within the nests there are a wide size-range of workers (as small as $0.8 \mathrm{mg}$; Wetterer, unpublished). The smaller workers are all lighter in color than the large foragers. Also within the nests, I found 
many light-colored workers of forager size. Almost certainly, these were callow (newly eclosed) workers. Only twice have I observed such light-colored workers outside the nest. All foragers collected in this study were darker, mature workers. Fowler (1983) noted that callow workers in Atta texana rarely foraged. Such temporal polyethism, division of labor by age, is almost universal among ants (Hölldobler and Wilson, 1990). Typically, young workers care for the brood and tend to other tasks within the nest, whereas older workers tend to nest construction, nest defense, and foraging.

\section{Discussion}

The foraging ecology of Ac. volcanus appears to be similar to that of its congener Ac. octospinosus. Both species primarily cut the leaves and other parts of small herbs and scavenge on fallen leaves, fruits, and flowers. Such selectivity is strikingly different from that of the sympatric leaf-cutter, A. cephalotes. Although some A. cephalotes foragers carry a variety of vegetable matter, the majority of foragers carry fresh leaf fragments cut from trees (Rockwood and Hubbell, 1987; Vasconcelos, 1990; Wetterer, 1990a).

Foragers of both Ac. volcanus and Ac. octospinosus are larger and with a narrower range of body mass than A. cephalotes foragers. Mean forager mass in A. cephalotes varies greatly among colonies and among trees attacked by any one colony (range of mean forager mass attacking individual trees: $4.2-11.1 \mathrm{mg}$; overall mean mass $\sim 7 \mathrm{mg}$; Wetterer, 1990a, ms). Even for A. cephalotes attacking an individual tree, the size-range of foragers is considerably broader than the 2.2-fold range of Ac. volcanus foragers for all colonies combined (typical mass range for A. cephalotes foragers attacking individual trees: 5- to 10 -fold, coefficient of variation (mean/SD): 0.3-0.7; Wetterer, 1990a, ms).

The differences in forager polymorphism between A. cephalotes and the two species of Acromyrmex may represent different foraging strategies that allow each species to harvest efficiently its preferred vegetation resources. A. cephalotes foragers often mass recruit to large trees in prolonged attacks lasting up to several days. In these attacks, the mass of recruited foragers is matched to the leaf source, with larger foragers attacking trees with thicker and tougher leaves (Nichols-Orians and Schultz, 1989; Wetterer, 
1990a, ms). The match of forager mass to leaf type increases both cutting efficiency (Wilson, 1980b) and transport efficiency (Wetterer, ms). Extreme polymorphism among foragers broadens the diversity of tree species that can be exploited efficiently. For species such as Ac. octospinosus and Ac. volcanus that depend primarily on cutting or collecting vegetation at small, ephemeral sources, matching worker size to resource type during the short duration of each attack at individual source may be economically impractical. A forager caste of a single optimal size that is large enough to harvest vegetation at all encountered sources may be more efficient.

Whereas the foraging ecology of Ac. volcanus is generally similar to its congener Ac. octospinosus, there is a striking difference in forager mass between these two species. The adaptive function of this difference may be related to Ac. volcanus' habit of collecting whole flowers, flower buds, and berries and cutting the thick leaves of epiphytes, tasks that require a larger forager caste.

The large size of Ac. volcanus foragers rivals the mass of typical soldiers of some Atta species, such as Atta colombica Guerin (Wetterer, unpublished data). A. colombica "soldiers" commonly forage (Wetterer, unpublished data) and the "foragers" of Ac. volcanus also act as soldiers, thus blurring one characteristic generally considered to distinguish the two genera (i.e., the presence of a soldier caste).

The terrestrial and arboreal nesting habits of Ac. volcanus were typical for Acromyrmex, and particularly similar to those reported for the other two Acromyrmex species known to occur in Costa Rica, Ac. octospinosus and Ac. coronatus. Ac. octospinosus typically nests in the soil (commonly in road banks), but also nests above the soil (Weber, 1945; Wetterer, personal observation). At La Selva, I most commonly found Ac. octospinosus nests in the soil at the base of trees. Only once did I find an Ac. octospinosus trail going up a tree presumably to an arboreal nest. Weber (1946) found Ac. coronatus nests "above ground, under fallen logs or in masses of rotted wood and humus on the buttress roots of fallen logs, covered by a loose layer of dead leaf fragments."

Further research is needed to confirm whether Ac. volcanus nesting habits are strictly arboreal at La Selva and at other low elevation sites, but more terrestrial at higher elevation and, if so, to determine the ecological significance of this shift in nesting habit. 
At lower elevation sites Ac. volcanus may be driven into the trees by greater competition from other ants (A. Bien, personal communication) or perhaps by greater predation pressure.

Ac. volcanus is more apparent at Plastico and Rara Avis than at La Selva. This difference, however, may not be due to a difference in abundance. At Rara Avis, Ac. volcanus may be more noticeable simply because it is the only common leaf-cutter present; Atta cephalotes, which is very common at La Selva and Plastico, is absent at Rara Avis. At Plastico, Ac. volcanus may be more apparent because of its terrestrial habits there and because it nests in road banks which are relatively clear of vegetation. It is possible that Ac. volcanus is quite abundant in the treetops of La Selva and other lowland forests in Central America. Ac. volcanus may be much more common and ecologically important than generally appreciated and certainly deserves additional study.

\section{SUMMARY}

I examined the foraging and nesting ecology of Acromyrmex volcanus Wheeler, a leaf-cutting ant known only from Northeastern Costa Rica. No previous study has examined any aspect of the ecology of this species. I compared its ecology with that of a close relative, the common and widespread Acromyrmex octospinosus Forel.

I found that Ac. volcanus depends heavily on cutting herbs and collecting pieces of fallen vegetation, such as dead leaves, fruit, petals, flower buds, and seeds. Such foraging selectivity is generally similar to that of Ac. octospinosus, although the nature of fruit and flower material carried by these two species of Acromyrmex differs. Ac. volcanus foragers often take whole berries and whole flowers and flower buds, whereas Ac. octospinosus foragers cut small pieces from larger fruits and flower petals.

Despite a 50 -fold range in worker mass within the nest (0.8 to $\sim 40 \mathrm{mg}$ ), Ac. volcanus foragers are relatively monomorphic, with only the very largest workers $(>20 \mathrm{mg}$ ) foraging. Such a pattern is again similar to that of Ac. octospinosus. Ac. volcanus foragers, however, are on average more than twice the mass of $A c$. octospinosus foragers ( $31 \mathrm{mg}$ vs. $13 \mathrm{mg}$ ). In fact, Ac. volcanus has the largest workers of any species of Acromyrmex. 
Ac. volcanus appears to nest most commonly in trees, but also nests on the ground. In both situations, the nests are found under several centimeters of organic debris. These nesting habits are typical of Acromyrmex. Ac. volcanus appears to be more arboreal in nature than Ac. octospinosus.

The large monomorphic foragers of $A c$. volcanus and $A c$. octospinosus appear to be well suited as generalist foragers, able to cut or collect any desirable vegetation encountered. Additional studies are needed to evaluate the ecological differences between these two species.

\section{ACKNOWLEDGMENTS}

I thank M. Wetterer, W. Piel, G. Dahlstrom, and G. Alpert for comments on this manuscript. I thank the students of the OTS 92-3 course, E. Foster and V. Kennard for their help and friendship at Plastico and at Rara Avis. Financial support was provided by the Organization for Tropical Studies, the American Philosophical Society, the National Geographic Society, and the National Science Foundation (grant BSR-9103782).

\section{LiteRATURE Cited}

FOWLER, H. G.

1983. Alloethism in a leaf-cutting ant: laboratory studies on Atta texana (Hymenoptera: Formicidae: Attini) Zool. Jb. Physiol. 87: 529-538.

HÖLLDOBLER, B. AND E. O. WILSON

1990. The Ants. Harvard University Press, Cambridge, Massachusetts.

Nichols-ORIANS, C. M. AND J. C. SChULTZ

1989. Leaf toughness affects leaf harvesting by the leaf-cutter ant, Atta cephalotes (L.) (Hymenoptera: Formicidae). Biotropica 21: 80-83.

Rockwood, L. L. AND S. P. HuBbelL

1987. Host plant selection, diet diversity, and optimal foraging in a tropical leafcutting ant. Oecologia 74: 55-61.

VASCONCELOS, H. L.

1990. Foraging activity of two species of leaf-cutting ants (Atta) in a primary forest of the central Amazon. Insectes Sociaux 37: 131-145.

WEBER, N. A.

1945. The biology of the fungus-growing ants. Part VIII. The Trinidad, B.W.I., species. Revista de Entomologia 16: 1-88.

1946. The biology of the fungus-growing ants. Part IX. The British Guiana species. Revista de Entomologia 17: 114-172.

1972. Gardening ants: the attines. American Philosophical Society. Philadelphia, Pennsylvania. 
WETTERER, J. K.

1990a. Diel changes in forager size, activity, and load selectivity in a tropical leaf-cutting ant, Atta cephalotes. Ecological Entomology 15: 97-104.

1990b. Load-size determination in leaf-cutting ants. Behavioral Ecology 1: 95-101.

1991a. Allometry and the geometry of leaf-cutting in Atta cephalotes. Behavioral Ecology and Sociobiology 29: 347-351.

1991b. Foraging ecology of the leaf-cutting ant, Acromyrmex octospinosus, in a Costa Rican rain forest. Psyche 98: 361-371.

ms. Forager polymorphism, size-matching, and load delivery in the leafcutting ant, Atta cephalotes. Submitted to Ecological Entomology

WHEELER, W. M.

1937. Mosaics and Other Anomalies Among Ants. Harvard University Press. Cambridge, Mass.

WILSON, E. O.

1980a. Caste and division of labor in leaf-cutter ants. I. The overall pattern in A. sexdens. Behavioral Ecology and Sociobiology 7: 143-156.

1980b. Caste and division of labor in leaf-cutter ants. II. The ergonomic organization of leaf cutting. Behavioral Ecology and Sociobiology 7: 157-165. 

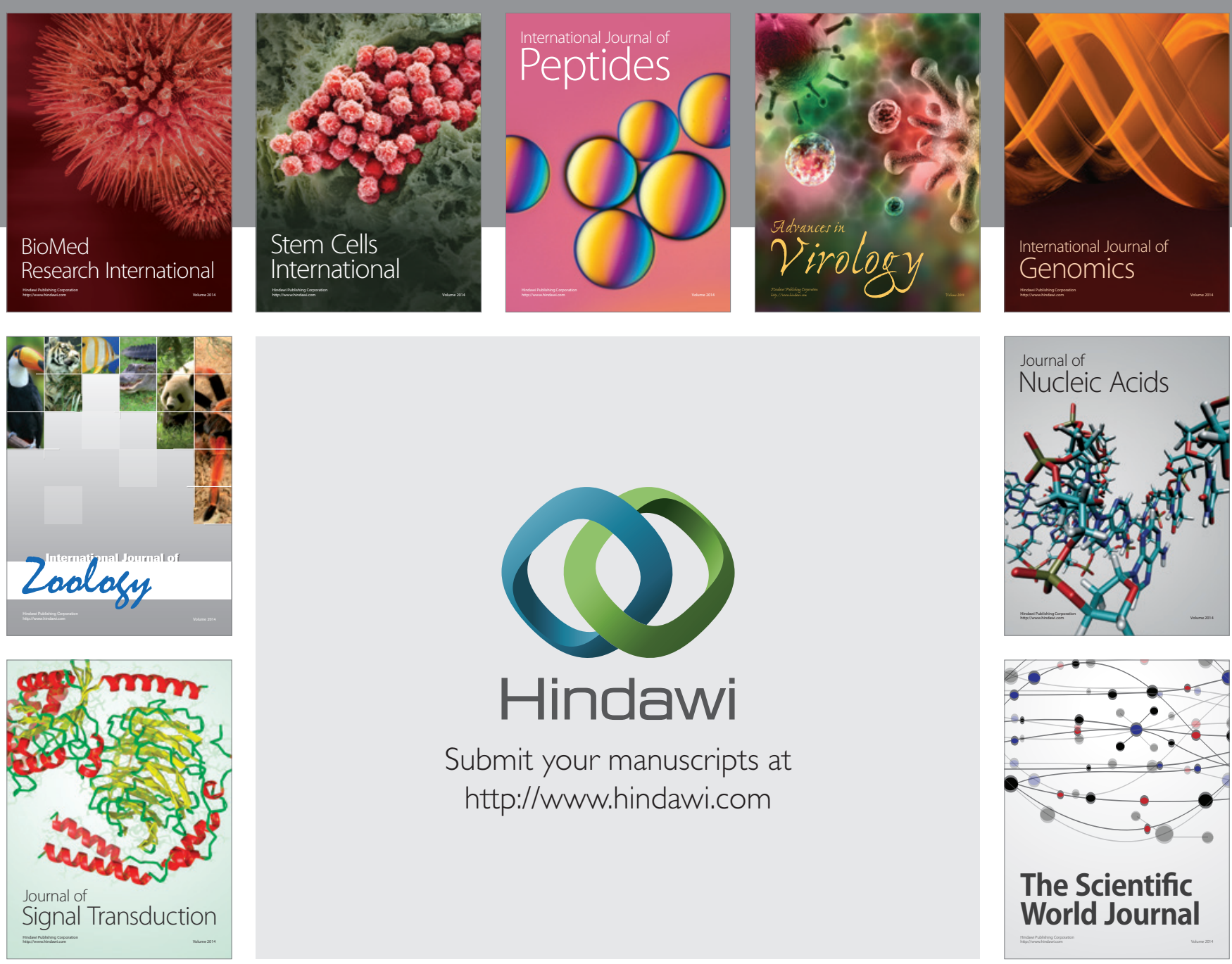

Submit your manuscripts at

http://www.hindawi.com
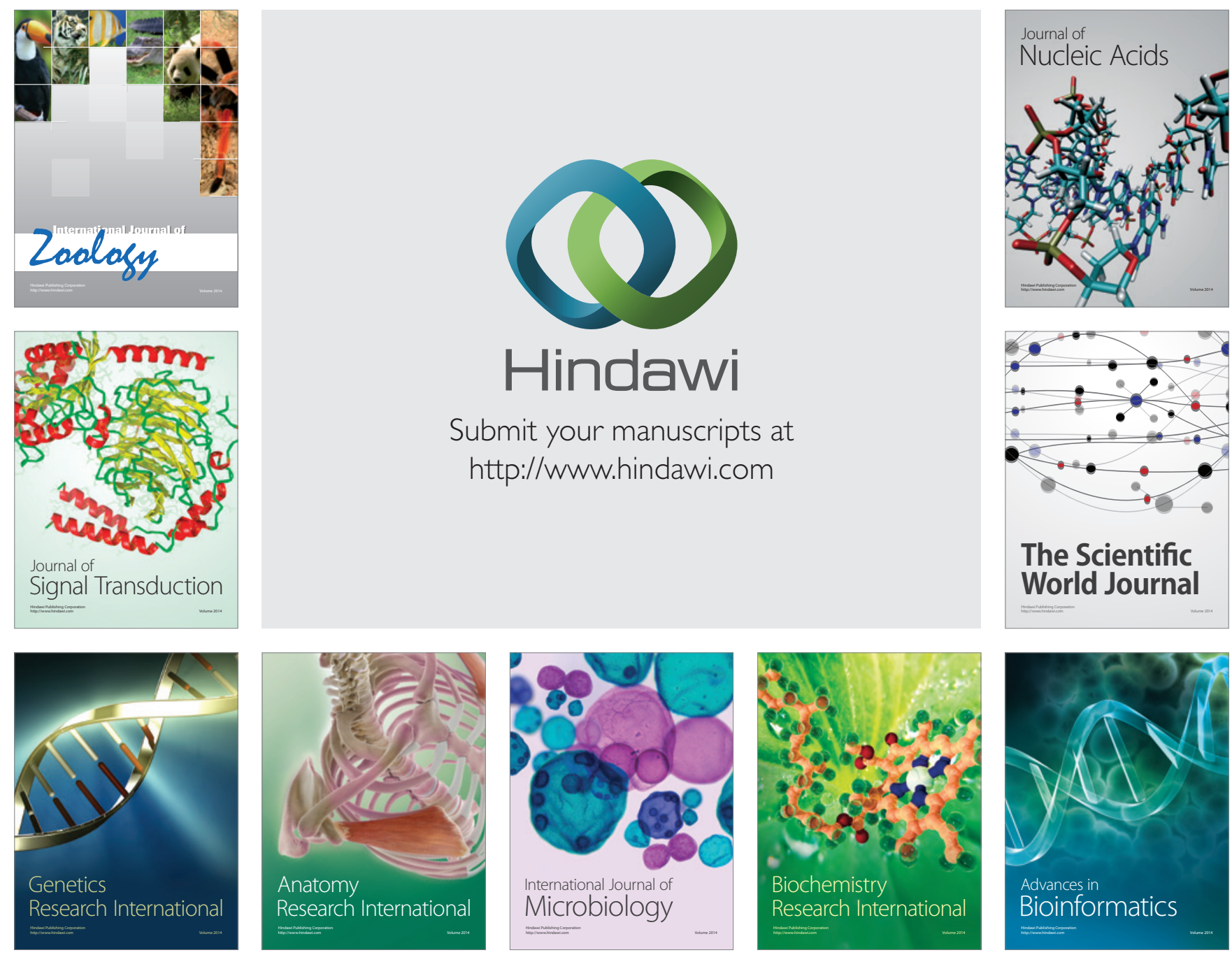

The Scientific World Journal
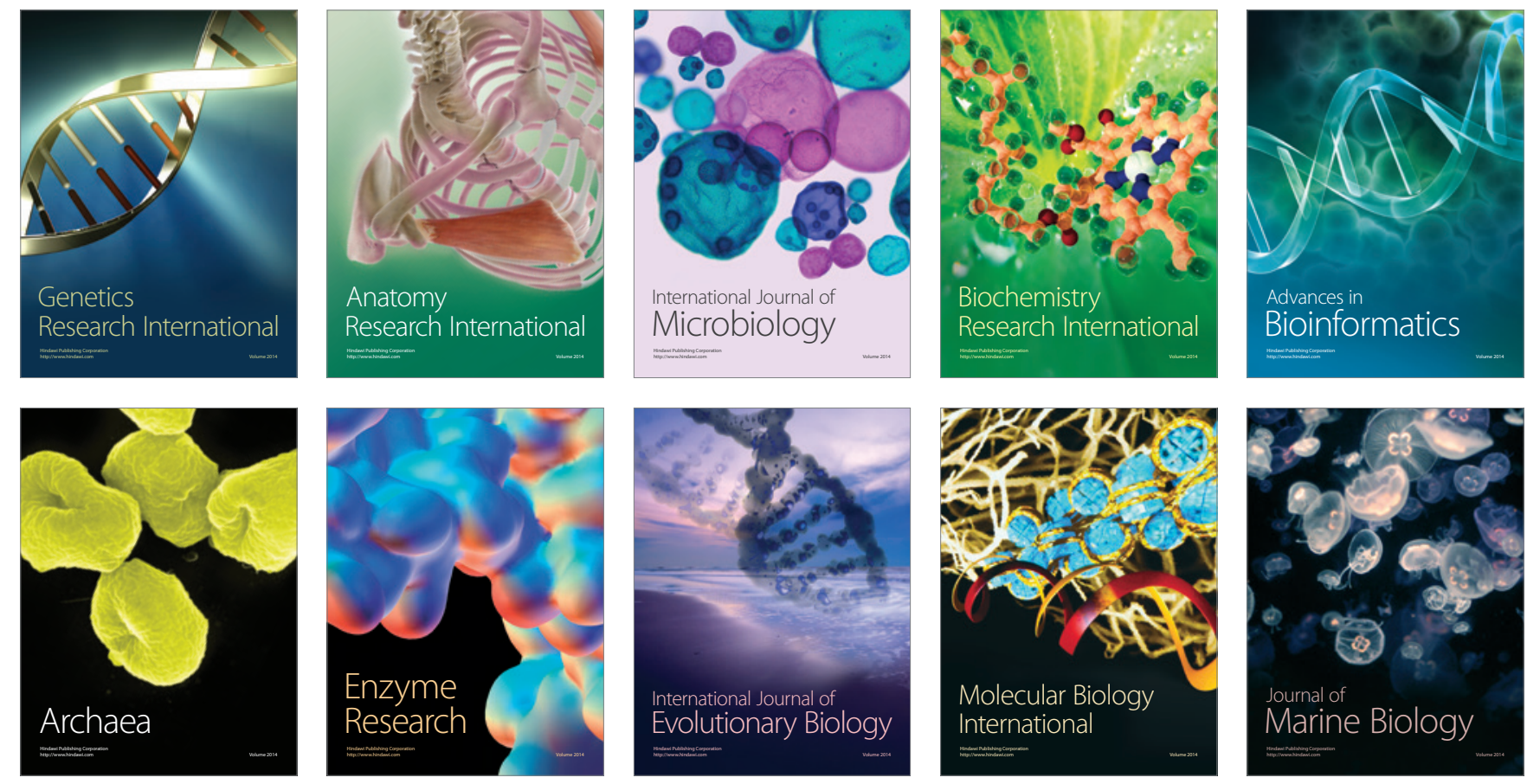